\title{
Notalgia Paresthetica Relieved by Cervical Traction
}

\author{
Rhonda Low, MD, CCFP, FCFP, FAAP, Leah A. Swanson, MD, \\ and David L. Swanson, MD, FAAD
}

\begin{abstract}
Notalgia paresthetica is a syndrome of unilateral, chronic pruritis that is associated with burning pain, paresthesia, numbness, and hyperesthesia localized to the medial and inferior scapula. The condition does not respond to anti-inflammatory drugs or traditional antipruritic agents and has variable responses to numerous other reported pharmacologic and nonpharmacologic therapies. Although the etiology is thought to be nerve impingement, neurologic and musculoskeletal causes are often not considered in the differential diagnosis. We present a report of a woman with a 2-year history of refractory notalgia paresthetica. Based on spinal imaging showing cervical neuroforaminal stenosis, the patient was prescribed a course of cervical traction. Her symptoms resolved and have not returned after 2 years of followup. We believe this is the first case report of successful treatment of notalgia paresthetica with cervical traction. (J Am Board Fam Med 2017;30:835-837.)
\end{abstract}

Keywords: Cervical Vertebrae, Pathophysiology, Pruritus, Spinal Diseases

Notalgia paresthetica, first described in 1934, is a unilateral pruritus located medial or inferior to the scapula. ${ }^{1}$ Burning pain, paresthesia, numbness, and hyperesthesia may accompany the itch. ${ }^{2}$ The condition is more prevalent in middle-aged women and is often chronic, lasting for years. ${ }^{1}$ The condition is similar to other forms of neuropathic itch or neurocutaneous dysesthesias, such as meralgia paresthetica and brachioradialis syndrome. Notalgia paresthetica is not believed to be rare, although it is not frequently reported or studied. ${ }^{3}$ A number of physical and pharmacologic therapies have been described, with variable results. Herein, we report a case of notalgia paresthetica that responded to cervical traction with permanent resolution of symptoms.

This article was externally peer reviewed.

Submitted 11 April 2017; revised 1 August 2017; accepted 1 August 2017.

From the Department Family \& Community Medicine, University of British Columbia, Vancouver, BC (RL); Department of Dermatology, Mayo Clinic, Scottsdale, AZ (LAS, DLS).

Funding: none.

Conflict of interest: none declared.

Corresponding author: David L. Swanson, MD, FAAD, Department of Dermatology, Mayo Clinic, 13400 E. Shea Blvd, Scottsdale, AZ 85259 (E-mail: swanson.david@mayo. edu).

\section{Case Report}

A 49-year-old woman presented with a 2-year history of increasing pruritus and skin sensitivity. She had a history of atopy and initially attributed the cause of the condition to a clothing allergy. The pruritus was localized to the left midscapular region, extending to the posterior and medial upper arm and axilla. The itch was present most of the day, occasionally wakening her from sleep at night, and was aggravated by hot weather and hot showers. Topical corticosteroid, ketamine, lidocaine, and menthol therapies provided only temporary relief.

On examination, there was slight hyperesthesia of the involved skin and a few excoriations but no evidence of dermatitis, induration, warmth, or swelling. A punch biopsy of the involved skin showed no pathologic findings. A computed tomographic scan of the patient's cervical spine revealed a small C5-C6 central disk herniation, not impacting the thecal sac. At the C7-T1 level, there was a mild to moderate, left-sided bony neuroforaminal stenosis with a possible $\mathrm{C} 8$ root compromise.

The patient was prescribed a 6-week course of cervical mechanical traction of the $\mathrm{C} 4-\mathrm{C} 7$ vertebrae and exercises to release the left upper trapezius and posterior shoulder capsule and to strengthen the lower trapezius, as well as posture education. 
The sessions gave temporary relief over the day. After completing the course of therapy, the patient tried a session of cervical chiropractic manipulation, which made her itch worse. After a 1-month hiatus, the patient returned for daily sessions of cervical traction, soft-tissue massage of the trapezius, and reiteration of posture education. Over the 4 sessions, the pruritus subsided, and it disappeared after the final session. The symptoms have not recurred after more than 2 years of followup.

\section{Discussion}

Notalgia paresthetica has been speculated to be a sensory nerve entrapment syndrome caused by damage to the cutaneous branches of the posterior division of spinal nerves. ${ }^{1,2}$ The nerves, especially at the T2-T6 region, emerge through the multifidus spinae muscle at right angles en route to the epidermis, rendering them exposed and more susceptible to injury. ${ }^{4}$ The nerves can also become entrapped as they exit the vertebral foramina. Studies have shown that over $60 \%$ of patients with notalgia paresthetica have degenerative vertebral changes or herniated discs that correspond with the dermatomal distribution of their symptoms. ${ }^{1}$ Savk et $\mathrm{al}^{3}$ reported a striking correlation of localization of notalgia paresthetica with degenerative changes in the spines of 10 patients, suggesting that spinal nerve impingement may be important to its pathogenesis. Notalgia paresthetica has also been reported with radiologic evidence of low cervical spinal compression. ${ }^{5}$

Traditional first-line antipruritic agents, such as antihistamines and topical corticosteroids, are ineffective for treating notalgia paresthetica. ${ }^{1}$ Case reports have shown variable improvement of itch with topical capsaicin ${ }^{6}$, lidocaine, and prilocaine topical cream (Emla cream) $)^{7}$, tacrolimus ointment ${ }^{8}$, cutaneous botulinum toxin type A injection ${ }^{9}$, local paravertebral nerve block ${ }^{10}$, transcutaneous electric nerve stimulation $^{11,12}$, surgical nerve decompression ${ }^{13}$, epidural steroid injections, and UVB light treatments ${ }^{14}$; and with the drugs gabapentin ${ }^{15}$, oxycarbazepine ${ }^{7}$, amitriptyline ${ }^{16}$, and phenytoin. ${ }^{1}$ However, these treatments are typically temporary, invasive, or expensive, or have potential side effects.

Physical therapeutic measures have also been reported to relieve the pruritus of notalgia paresthetica. In 2 women, exercises to strengthen postural muscles ${ }^{17}$ and extend the spine were effective in reducing the angle that the cutaneous nerves passed through the rhomboid and trapezius muscles, thereby relieving itch. ${ }^{4}$ Deep, intramuscularstimulation acupuncture was temporarily effective in 16 patients, with recurrence of symptoms between 1 and 12 months. ${ }^{18}$ Osteopathic manipulative treatment successfully treated 1 woman with notalgia paresthetica. ${ }^{19}$

In busy primary-care settings, providers may overlook possible biomechanical and neurologic causes of notalgia paresthetica. A comprehensive history and examination for cervical spondylosis, disk disease, radiculopathy, or prior trauma are important in the assessment of notalgia paresthetica. In addition, alternative diagnoses should be considered, including primary skin diseases, such as contact or atopic dermatitis, or other neuropathic disorders, such as postherpetic neuralgia or multiple sclerosis. Our patient did not have any evidence of a primary skin or other neurologic disease as the source of her symptoms, and a skin biopsy showed no features characteristic of dermatitis. Although she said that she had clothing intolerance, the intolerance was probably a consequence of the hyperesthesia from her nerve compression.

This is the first report, to our knowledge, of the use of cervical traction for notalgia paresthetica. Our patient's condition responded with permanent remission after a limited therapeutic course of cervical traction, physical therapy, and posture education. We believe the cervical traction was the more important component of the therapy. A trial of cervical traction seems a reasonable therapeutic option for patients, considering the current understanding of pathophysiology of notalgia paresthetica, and it has the advantage of being safe and relatively inexpensive. This is especially true if diagnostic imaging supports nerve impingement as the cause. Ultimately, more investigative work needs to be done to prove efficacy.

To see this article online, please go to: http://jabfm.org/content/ 30/6/835.full.

\section{References}

1. Ellis C. Notalgia paresthetica: The unreachable itch. Dermatol Pract Concept 2013;3:3-6.

2. Yosipovitch G, Samuel LS. Neuropathic and psychogenic itch. Dermatol Ther 2008;21(1):32-41.

3. Savk E, Savk O, Bolukbasi O, et al. Notalgia paresthetica: A study on pathogenesis. Int J Dermatol 2000;39:754-759. 
4. Fleischer AB, Meade TJ, Fleischer AB. Notalgia paresthetica: Successful treatment with exercises. Acta Derm Venereol 2011;91:356-357.

5. Alai NN, Skinner HB, Nabili ST, Jeffes E, Shahrokni S, Saemi AM. Notalgia paresthetica associated with cervical spinal stenosis and cervicothoracic disk disease at C4 through C7. Cutis 2010;85:77-81.

6. Leibsohn E. Treatment of notalgia paresthetica with capsaicin. Cutis 1992;49:335-336.

7. Savk E, Bolukbasi O, Akyol A, Karaman G. Open pilot study on oxcarbazepine for the treatment of notalgia paresthetica. J Am Acad Dermatol 2001;45: $630-632$.

8. Ochi H, Tan LX, Tey HL. Notalgia paresthetica: Treatment with topical tacrolimus. J Eur Acad Dermatol Venereol 2016;30:452-454.

9. Maari C, Marchessault P, Bissonnette R. Treatment of notalgia paresthetica with botulinum toxin A: A double-blind randomized controlled trial. J Am Acad Dermatol 2014;70:1139-1141.

10. Goulden V, Toomey PJ, Highet AS. Successful treatment of notalgia paresthetica with a paravertebral local anesthetic block. J Am Acad Dermatol 1998;38:114-116.

11. Savk E, Savk O, Sendur F. Transcutaneous electrical nerve stimulation offers partial relief in notalgia paresthetica patients with a relevant spinal pathology. J Dermatol 2007;34:315-319.
12. Wang CK, Gowda A, Barad M, Mackey SC, Carroll IR. Serratus muscle stimulation effectively treats notalgia paresthetica caused by long thoracic nerve dysfunction: A case series. J Brachial Plex Peripher Nerve Inj 2009;4:17.

13. Williams EH, Rosson GD, Elsamanoudi I, Dellon AL. Surgical decompression for notalgia paresthetica: A case report. Microsurgery 2010;30: 70-72.

14. Pérez-Pérez L, Allegue F, Fabeiro JM, Caeiro JL, Zulaica A. Notalgia paresthesica successfully treated with narrow-band UVB: Report of five cases. J Eur Acad Dermatol Venereol 2010;24:730-732.

15. Maciel AA, Cunha PR, Laraia IO, Trevisan F. Efficacy of gabapentin in the improvement of pruritus and quality of life of patients with nostalgia paresthetica. An Bras Dermatol 2014;89:570-575.

16. Yeo B, Tey HL. Effective treatment of notalgia paresthetica with amitriptyline. J Dermatol 2013;40: 505-506.

17. Ikoma A, Cevikbas F, Kempkes C, Steinhoff $M$. Anatomy and neurophysiology of pruritus. Semin Cutan Med Surg 2011;30:64-70.

18. Stellon A. Neurogenic pruritus: An unrecognised problem? A retrospective case series of treatment by acupuncture. Acupunct Med 2002;20:186-90.

19. Richardson BS, Way BV, Speece AJ 3rd. Osteopathic manipulative treatment in the management of notalgia paresthetica. J Am Osteopath Assoc 2009; 109:605-608. 